RESEARCH REPORT

\title{
EFFECTIVENESS OF MANUAL TRACTION IN COMPARISON TO ELECTROTHERAPY (TRANSCUTANEOUS ELECTRICAL NERVE STIMULATION - TENS) IN THE TREATMENT OF KNEE OSTEOARTHRITIS
}

\begin{abstract}
\section{OBJECTIVE}

To determine the effects of manual traction in knee arthritis patients in comparison to electrotherapy (TENS).

\section{STUDY DESIGN}

Randomized Control Trial (Experimental Study).

\section{STUDY SETTINGS \& PARTICIPANTS}

Study was conducted in a Tertiary Care Hospital with a sample of 310 participants.

\section{INTERVENTIONS}

Manual traction and Electrotherapy Transcutaneous electrical nerve stimulation (TENS) will be used to manage pain in patients with Knee Osteoarthritis.

\section{OUTCOME MEASURES}

Oxford Knee Pain Scale was used to measure pain and functional activities.

\section{RESULTS}

Improvements were seen in both groups but results of manual traction were more significant. There were major differences present in knee pain intensity before and after treatment. The group that received manual traction reported a decrease in the severity of pain of mean 15.01 which is comparatively better than the group that received electro therapy and reported a decrease in severity of pain of mean 12.42 .
\end{abstract}

\section{CONCLUSION}

The result of this research supports the application of manual TF joint traction as a mean of stretching shortened articular and periarticular tissues with decreased in levels of pain either during the treatment or at the end of session. There is significant improvement in knee flexion AROM. Pain level decreases during every treatment session.

\section{KEY WORDS}

Knee Pain, Traction, Mobilization, Tibio-Femoral Joint, TENS, Knee OA.

\author{
Sunny Kumar \\ Physiotherapist \\ Ziauddin Hospital Clifton
}

\author{
M. Usman Khan \\ Senior Lecturer \\ Ziauddin College of Physical Therapy \\ m_khanusman@hotmail.com \\ Qurat ul Ain Adnan \\ Senior Lecturer \\ Ziauddin College of Physical Therapy \\ Ziauddin University \\ aqua_84282hotmail.com
}

[Kumar S, Khan MU, Adnan QA. Effectiveness of Manual Traction in Comparison to Electrotherapy in the Treatment of Knee Osteoarthritis. Pak. J. rehabil.2014;3(2):26-30] 


\section{INTRODUCTION}

Knee pain is known as one of the frequently reported cases involving musculoskeletal conditions, $22-23 \%$ of the population suffer from the condition around the age of 65 years. Osteoarthritis is the most common type of arthritis, according to the National Health Service, USA. 8.5 million People are affected by this condition. The arthritis foundation of USA, also states that almost 27 million of Americans are suffering from this condition'. Prevalence rates are higher in females than in males ${ }^{2}$.The knee joint, along with other major weight bearing joints of the body including hip joints and spine are more prone to damage by going through degenerative changes ${ }^{3}$.

Osteoarthritis is usually the main cause of knee pain in elderly individuals ${ }^{4}$. Knee osteoarthritis produces significant changes which may affect many other aspects of life including health related quality of life, physical, mental and social components of health are affected by these degenerative changes.

Osteoarthritis is a progressive, irreversible disease. Signs and symptoms gradually get worse over a period of time. Since it is an irreversible disease, there is no cure. However, available therapies may help with pain reduction, subside inflammation and swelling. These therapies also play an important role in muscle strengthening, to keep the patients mobile and active. Experts say that patients who take steps to actively manage their osteoarthritis are more likely to overcome their symptoms.

Motion impairments attributed to many other causes which includes immobilization following any injury ${ }^{5}$ surgical interventions to repair or remove menisci ${ }^{6,7}$ and osteoarthritis 8,9 , itself.

Soft tissue changes around the knee joint can lead to decrease in strength of the quadriceps muscles and sagital range of motion, which may further lead to increased soft tissue contracture. ${ }^{10}$ These changes all together produce a typical clinical picture of joint pain, and stiffness at rest.

These symptoms further lead to difficulty face by patients to perform daily activities and weight bearing. This facilitates progression in disability. ${ }^{11}$

The treatment of knee osteoarthritis is currently limited to symptoms management, rather than progression control ${ }^{12}$ An evidence based approach to management of osteoarthritis should include patient guidance and awareness about the disease, pain control, options to improve functions, decrease disability, and prevent disease progression $^{13}$.

Treatments commonly available involve pharmacological treatments, non-pharmacological strategies and surgical interventions. Analgesics and anti-inflammatory drugs are widely used in management ${ }^{14}$, despite known serious adverse effects associated with long term NSAID use ${ }^{15,16}$

Paracetamol is known as primary oral analgesic, if successful the long term use preferred. These types of therapies help to deal with symptoms. Osteoarthritis is often viewed as a problem of biomechanical functions. In order to treat the large and growing numbers of sufferer's various treatment options besides the use of medicine are utilized. Thus, many patients visit practitioners who provide therapies which intend to improve functional activities. Concerns regarding lost function, include ability to ambulate are addressed through different forms of physical therapy. These therapies include strength-based and exercise program to achieve their long term goal that is functional capability and ambulation.

Treatment plan consisting of an aerobic walking and strengthening exercises of quadriceps give desired results 17.

For the treatment of pain and motion impairment(s) the healthcare professionals in spine and peripheral joints utilize their purpose of joint mobilization for treatment. Most of the research studies used techniques that are aimed at the spine and upper extremities, with a lesser amount of evidence for the efficacy of lower extremities mobilization. The manual therapy shows effective results in improving flexion of knee joint also shows effectiveness in climbing stairs in patients suffering from anterior knee pain and also little amount of improvement in knee pain ${ }^{17}$.

Muscle strength, proprioception and functional performance seems to be effectively improved when manual therapy combined with appropriate exercise therapy, then just a randomized exercise therapy. When muscle strength is lost and there is decreased activity of extensors of knee found to be associated with anterior knee pain, this refers to muscle inhibition. Sacroiliac joint manipulation helped to overcome muscle inhibition of knee extensors. What muscle function benefited, so spinal manipulation known to have effective results in muscle inhibition of lower limb musculatures ${ }^{17}$.

Studies precise to knee joint are focused on mobilization, which includes anterior/posterior joint mobilization as well as patellar glides to improve outcomes in patients with knee pain. Different sort of treatment strategies is suggested, which aim to reduce pain and prevent functional deterioration in future ${ }^{17,18}$. Traction is applied at a right angle to the treatment plane, which is for the tibiofemoral joint, is located in the concave proximal end of the tibia.

Kalten born defined a grading system for traction. There are three types of tractions. According to the above mentioned grading, grade III of the traction is linear motion, applied with sufficient force to take up the slake in the joint capsule. Ensure that the soft tissues surrounding the knee joint become taut.

Studies done in the past had shown that TENS increases pain and heat threshold in healthy individuals. Transcutaneous electrical nerve stimulator is an inexpensive, non-invasive intervention used in various painful conditions ${ }^{19}$.

TENS has a better effect in pain that is being evoked by movements, also shows beneficial results by providing functional improvement ${ }^{20}$. Application of tens is through four self-adhesive electrodes that are place in a bucket method surrounding the knee joint with OA for 20 minutes at a comfortable intensity ${ }^{21}$. The specific site for electrode placement is determined by the allocation examiner using point of least impedance ${ }^{22}$.

The intention of this research was to determine before session condition and changes after the treatment session is provided by TENS and by manual therapy. Manual therapy is joint traction and mobilization on measures of pain. 


\section{Traction Grading}

Kalten born Traction Grading Scale

Grade I - Neutralizes joint pressure without separation of joint surfaces

Grade II - Separates articulating surfaces, taking up slack or eliminating play within joint capsule

Grade III - Stretching of soft tissue surrounding joint

Transcutaneous Electrical Nerve Stimulation (TENS)

It is a non-invasive modality with very few adverse effects that is used in physiotherapy for control of pain. Seven studies using TENS in people with knee osteoarthritis (OA) were identified for this review; device setting, application and outcomes measured varied between studies ${ }^{23}$.

\section{METHODOLOGY}

\section{Study Design}

Randomized Control Trial (Experimental study)

\section{Setting}

Research was conducted at Outpatient Department of tertiary care hospital.

\section{Duration of Study}

6 months.

\section{Sample Size}

Sample size was calculated as 309.7 taking prevalence of knee OA 22-28\% ${ }^{24}$, at $95 \%$ confidence level and margin of error is 0.05 . To avoid data wastage 310 Individual will be included in the study.

\section{Sampling Techniques}

Simple Random Sampling

\section{Sample Selection} Inclusion Criteria

Individuals coming for physiotherapy treatment diagnosed with Knee Osteoarthritis between the age group of 40 to 75 .

\section{Exclusion Criteria \\ 1. Osteoporosis \\ 2. Knee joint infection \\ 3. Acute rheumatoid arthritis}

Pain referred from hip, sacroiliac, and lumbar spine.

1. A ligament injury

2. Cognitive deficits

3. Patello femoral arthritis.

Data Collection Tool

Date was collected using Oxford Knee Pain Scale Questionnaire.

\section{Data Analysis}

Statistical package for social science (SPSS-20) was used to analyze data, means and standard deviation of all quantitative parameters, for effect was calculated other qualitative parameters.

\section{RESULTS}

Table 1.01 participants

A sample of 310 participants including 62 males and 248 females, participated in this research, which measured outcomes over sessions. Therefore, results for OKPS data

\begin{tabular}{|c|c|c|c|c|c|}
\hline \multicolumn{6}{|c|}{ Table 1.01 participants } \\
\hline Sex & Freq. & $\%$ & $\begin{array}{c}\text { Valid } \\
\%\end{array}$ & $\begin{array}{c}\text { Cumulat } \\
\text { ive\% }\end{array}$ & \\
\hline Valid & F & 248 & 80.0 & 80.0 & 80.0 \\
\hline & M & 62 & 20.0 & 20.0 & 100.0 \\
\hline & Total & 310 & 100.0 & 100.0 & \\
\hline
\end{tabular}

included all participants. No participant discontinued treatment due to increased knee pain. All participants completed all session.

Table 1.02 mean and std. deviation of age The mean age $( \pm 9.61)$ for all participants was 54.40 years.

\begin{tabular}{|cc|c|c|c|c|}
\hline \multicolumn{3}{|c|}{ Table 1.02 mean and std. deviation of age } \\
\hline $\begin{array}{c}\text { Descriptive } \\
\text { Statistics }\end{array}$ & $\mathrm{N}$ & Min. & Max. & Mean & $\begin{array}{c}\text { Std. } \\
\text { Deviati } \\
\text { on }\end{array}$ \\
\hline Age & 310 & 40.00 & 74.00 & 54.40 & 9.61 \\
\hline $\begin{array}{c}\text { ValidN } \\
\text { (list wise) }\end{array}$ & 310 & & & & \\
\hline
\end{tabular}

\begin{tabular}{|c|c|c|c|c|c|c|}
\hline \multicolumn{7}{|c|}{ Table 1.03 Mean Value of Intervention } \\
\hline Group & & N & Mean & $\begin{array}{c}\text { Std. } \\
\text { Deviati } \\
\text { on }\end{array}$ & Min. & Max. \\
\hline \multirow[t]{2}{*}{ Traction } & $\begin{array}{l}\text { Pre } \\
\text { total } \\
\text { score }\end{array}$ & 158 & 35.75 & 6.19 & 24 & 47 \\
\hline & $\begin{array}{l}\text { Post } \\
\text { total } \\
\text { score }\end{array}$ & 158 & 20.73 & 3.90 & 15 & 30 \\
\hline \multirow[t]{2}{*}{$\begin{array}{c}\text { Electro } \\
\text { therapy }\end{array}$} & $\begin{array}{l}\text { Pre } \\
\text { total } \\
\text { score }\end{array}$ & 152 & 50.65 & 3.43 & 44 & 57 \\
\hline & $\begin{array}{l}\text { Post } \\
\text { total } \\
\text { score }\end{array}$ & 152 & 38.23 & 5.47 & 21 & 43 \\
\hline
\end{tabular}

The mean value for active knee flexion AROM before intervention was 35.74 compared to 20.73 after the last intervention. This change between first and last recorded measurement of active knee flexion represented a mean increase of 15.01 in the all participants. The difference of 15.01 was statistically significant. On the other hand the mean value for electrotherapy before intervention was 50.65 compared to 38.23 after the last intervention. 


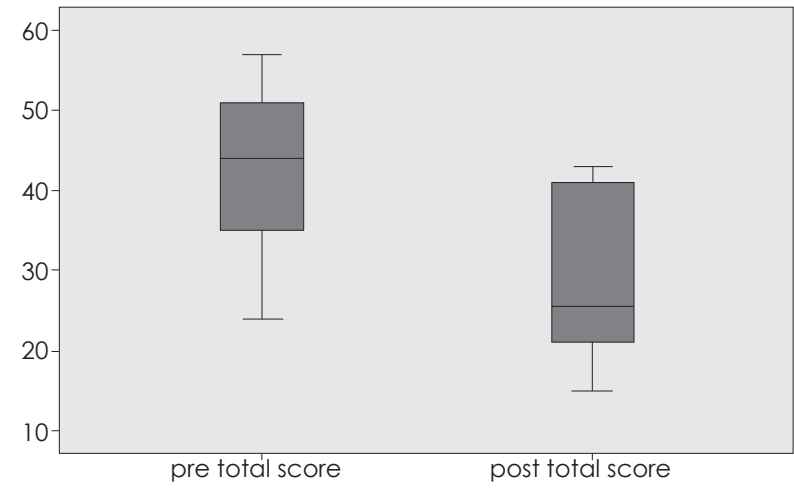

The mean difference was 12.42. Electro therapy (TENS) also significant but less than manual traction.

\section{DISCUSSION}

After the completion of following therapeutic session of end-range manual traction mobilization applied to the tibio femoral joint, there was significant improvement in knee flexion AROM. The research participants experienced a mean increase of 15.01 in active knee flexion which was measured before starting the treatment and measurements taken after the completion of therapy. This research utilized a therapeutic intervention applied manually, giving traction to articular surfaces and also stretching particular soft tissues in the region of both knee joints. The efficacy of the applied manual technique may relate to its application at the available range of motion. As well, manual traction applied over the TF joint may temporarily diminish the compression on the meniscus and facilitate the movement of fluid within the joint. The effects may help to subside the pain and swelling by decreasing the potential motion-limiting effects ${ }^{25}$.

According to Maher et al significant differences were observed in passive range of motion after the application of 2 minutes and 4 minutes of joint traction with no significance noted after 4 minutes. While pain felt by the individuals did not change significantly over time, but level of pain did change during each session of therapy ${ }^{26}$. It was evident in our data that manual traction showed better results in patients with knee osteoarthritis pain.

In another article by Polard $\mathrm{H}$ et al stated that a short-term manual therapy knee protocol found effective in pain reduction in research participants suffering from osteoarthritic knee pain. This resulted in great improvement in knee functions immediately after the end of second week of treatment session ${ }^{27}$. In our study we had similar results and the manual traction has been extremely effective as a treatment option.

The research participants show a statically significant change in active flexion of knee during every therapeutic session, due to which application of manual traction to the joint to improve knee flexion impairment is highly supported. The results of the study done shows statically significant changes after the treatment. We are also aware of the studies done, which also have reported these findings. Although the manual traction application to the tibiofemoral component did not produce a statically significant decline in knee pain when applied at a painful end range position, but level of pain did statically decrease during each treatment session. All members agreed and reported that they observe that the application of this manual technique lead to decrease their knee pain.

The exact mechanism for the perceived pain decline by the application of manual traction or mechanical traction technique is not well understood, Although theoretically it is corelated with increase in synovial fluid circulation, stimulation of articular receptor, tissue extensibility enhancement also transient decrease of compressive loads on the articular surfaces ${ }^{28}$.

\section{CONCLUSION}

The result of this research supports the application of manual TF joint traction as a mean of stretching shortened articular and periarticular tissues with decreased in levels of pain either during the treatment or at the end of session. There is significant improvement in knee flexion AROM. Pain level decreases during every treatment session.

\section{REFERENCES}

[1] Dillon CF, Rasch EK, Gu Q, Hirsch R. Prevalence of knee osteoarthritis in the United States: arthritis data from the third National Health and Nutrition Examination Survey. J Rheumatol. 2006;33:2271-9.

[2] Cunningham LS, Kelsey JL. Epidemiology of musculoskeletal impairments and associated disability. Am J Public Health 1984; 74(6):574-9.

[3] Altman R, Asch E, Bloch D, Bole G, Borenstein D, Brandt $K$ et al. Development of criteria for the classification and reporting of osteoarthritis: classification of osteoarthritis of the knee. Arthritis Rheum. 1986:29(8):1039-1049.

[4] Felson DT. Epidemiology of hip and knee OA. Epidemiologic Reviews. 2008;10:1-24.

[5] Van den Dolder PA, Roberts DL. Six sessions of manual therapy increase knee flexion and improve activity in people with anterior knee pain: a randomized controlled trial. Aust J Physiother 2006:52(4):261-4.

[6] Fairbanks TJ. Knee joint changes after meniscectomy. J Bone Joint Surg Am 2008;30:664-70.

[7] Goldlblatt JP, Smith S. Managing meniscal injuries: the treatment. More aggressive procedures are being attempted for repair and replacement. J Musculoskelet Med 2005;22:183-7.

[8] Szebenyi B, Hollander AP, Dieppe P, Quilty B, Duddy J, Clarke $S$, et al. Associations between pain, function, and radiographic features in osteoarthritis of the knee. Arthritis Rheum 2006;54: 230-5.

[9] Ozdemir F, Tukenmez O, Kokino S, Turan FN. How do marginal osteophytes, joint space narrowing, and range of motion affect each other in patients with knee osteoarthritis? Rheumatol Int Apr 2006;26(6):516-22.

[10] Scott WN, Insall JN, Kelly MA. Arthroscopy and Meniscectomy: Surgical Approaches, Anatomy, and techniques. In: Insall JN, editor. Surgery of the knee. New York: Churchill Livingstone; 2003.165-216.

[11] Mahajan A, Verma S, Tandon V. osteoarthritis. J Assoc Physicians India. Jul 2005:53:634-641.

[12] Jackson BD, Wluka AE, Teichtahl AJ, Morris ME, Cicuttini FM. Reviewing knee osteoarthritis - a biomechanical perspective. J Sci Med Sport. 2004;7(3):347-357.

[13] Jordan KM, Arden NK, Doherty M, et al. an evidence 
based approach to the management of knee osteoarthritis: Report of a Task Force of the Standing Committee for International Clinical Studies Including Therapeutic Trials (ESCISIT) Ann Rheum Dis. 2003;62(12):1 145-1155

[14] McColl GJ. Pharmacological therapies for the treatment of osteoarthritis. Med J Aust. 2001;175 (Suppl):S108-111.

[15] Pham K, Hirschberg R. Global safety of coxibs and NSAIDs. Curr Top Med Chem. 2005;5(5):465-473.

[16] Dieppe PA, Frankel SJ, Toth B. Is research into the treatment of osteoarthritis with NSAID's misdirected? Lancet. Feb 1993;341 (8841):353-354.

[17] Smidt N, de Vet HC, Bouter LM, Dekker J, Arendzen $\mathrm{JH}$, de Bie RA, et al. "Effectiveness of exercise therapy: a best-evidence summary of systematic reviews," Aust J Physiother, 2005;51 (2):71-85.

[18] Bellamy N, Campbell J, Robinson V, Gee T, Bourne R, Wells $G$. "Viscosupplementation for the treatment of osteoarthritis of the knee," Cochrane Database of Systematic Reviews, vol. 18, 2005.

[19] Chesterton LS, Barlas P, Foster NE, Lundeberg T, Wright CC, Baxter GD. Sensory stimulation (TENS): effects of parameter manipulation on mechanical pain thresholds in healthy human subjects. Pain. 2002;99(1-2):253-262.

[20] Rakel B, Frantz R. Effectiveness of transcutaneous electrical nerve stimulation on postoperative pain with movement. J Pain. 2003;4(8):455-464.
[21] Law PP, Cheing GL. Optimal stimulation frequency of transcutaneous electrical nerve stimulation on people with knee osteoarthritis. J Rehabil Med. 2004;36:220-225.

[22] Kaltenborn F. M. Manual Mobilization of the Joints: The Kaltenborn Method of Joint Examination and Treatment. Vol 1. 6th ed. Vol. 78 Oslo, Norway: Olaf Norlis Bokhandel; 2002.

[23] Osiri M, Welch V, Brosseau L, Shea B. Transcutaneous electrical nerve stimulation for knee osteoarthritis, Department of Medicine, General Hospital, Ottawa, Ontario, Canada: [Cochrane Database Syst Rev. 2009] JUL 8;2009.

[24] Anita YN, Doherty M. What of Guide Lines for Osteoarthritis. Int J Rhem Dis $2011 ; 14(2): 136-44$.

[25] Nordin M, Frankel V. Basic biomechanics of the musculoskeletal system. 2nd ed. Philadelphia, PA: Lea and Febiger; 1989.

[26] Sara M, Doug C Melodie K, John K, Xianggui Q. The effects of Tibio-femoral traction mobilization on passive knee flexion motion impairment and pain, JMMT 2010;18(1):29-36.

[27] Pollard H, Ward G, Hoskins W et al. The effect of a manual therapy knee protocol on osteoarthritic knee pain, Dec 2008;52(4):229-242.

[28] Aldegheri R, Grianpaolo T, Saleh M. Articulated distraction of the hip: conservative surgery for arthritis in young patients. Clin Orthop Relat Res 2004:301:94-101. 